\title{
Erratum to: Performance Evaluation of IEEE 802.11 DCF in Single Hop Ad Hoc Networks
}

\author{
Neeraj Gupta ${ }^{1}$ Chandra Shekhar Rai ${ }^{2}$
}

Published online: 12 May 2015

(C) Springer Science+Business Media New York 2015

\section{Erratum to: Wireless Pers Commun (2014) 79:2171-2193 DOI 10.1007/s11277-014-1979-5}

Equation (27) in the original publication should have read as shown below, including the stationary probability and its specification in an additional Eq. (28).

$$
\tau=b_{(0,0) e}\left(\frac{q^{2} W_{0}}{(1-p)(1-q)\left(1-(1-q)^{W_{0}}\right)}-\frac{q^{2}(1-p)}{(1-q)}\right)
$$

Here $b_{(0,0)}$ is stationary probability of a node such that backoff process is complete and there is no packet available for transmission.

$$
\begin{aligned}
\frac{1}{b_{(0,0) e}}= & (1-q)+\frac{q^{2} W_{0}\left(W_{0}+1\right)}{2(1-q)\left(1-(1-q)^{W_{o}}\right)}+\frac{q\left(W_{0}+1\right)\left(p(1-q)-q(1-p)^{2}\right)}{2(1-q)} \\
& +\frac{p q^{2}}{2(1-q)(1-p)}\left[\frac{W_{0}}{1-(1-q)^{W_{0}}}-(1-p)^{2}\right]\left[\frac{2 W_{0}\left(1-p-p(2 p)^{m-1}\right)}{1-2 p}+1\right]
\end{aligned}
$$

The online version of the original article can be found under doi:10.1007/s11277-014-1979-5.

Neeraj Gupta

neerajgupta37@rediffmail.com

1 School of Engineering and Technology, CSE Department, K.R. Mangalam University, Gurgaon, India

2 USICT, GGS Indraprastha University, Delhi, India 